\title{
A self-determination theory perspective on student success in attaining an emergency care degree
}

\author{
S Sobuwa, ${ }^{1} \mathrm{PhD} ;$ B Lord, ${ }^{2} \mathrm{PhD}$ \\ ${ }^{1}$ Department of Emergency Medical Care and Rescue, Faculty of Health Sciences, Durban University of Technology, South Africa \\ ${ }^{2}$ Department of Community Emergency Health and Paramedic Practice, Monash University, Melbourne, Australia
}

Corresponding author: S Sobuwa (simpiwesobuwa@gmail.com)

\begin{abstract}
Background. While student enrolment has increased in the South African (SA) higher education system, the undergraduate throughput rate has been abysmal. Consequently, the literature has largely focused on the negative discourse of understanding the hindrance of student success in higher education. Objectives. To take a positive discourse viewpoint of understanding student success in the Bachelor of Emergency Medical Care (BEMC) degree in SA The paper uses Deci and Ryan's self-determination theory to explore students' motivation to succeed in attaining the BEMC degree in SA.

Methods. Participants were BEMC students recruited from 4 universities. Third- and fourth-year students who had not repeated a module/subject while studying for the BEMC degree were purposively sampled and invited to join the focus group discussions. These groups were conducted at the respective institutions during the participants' free time. The audio recordings were transcribed to produce a written text of the focus group discussions. Thematic analysis was used to analyse the data with the aid of NVivo 11 (Microsoft, USA).

Results. The thematic analysis yielded two themes, i.e. intrinsic and extrinsic motivation. Some students were intrinsically motivated to complete the degree in the minimum time. It is more likely that students' intrinsic motivation increased with continued success in the programme and that it also satisfied their feeling of competence. Some students succeeded owing to extrinsic motivational factors - to prove some people wrong or because of the financial implications of failure.

Conclusion. The emergency care departments need to assist students to maintain motivation, which may satisfy their feelings of autonomy and competence. Addressing students' motivation may allow for more continued success in the academic programme.
\end{abstract}

Afr J Health Professions Educ 2019;11(4):114-117. https://doi.org/10.7196/AJHPE.2019.v11i4.6

While student enrolment has grown in the South African (SA) higher education system, the undergraduate throughput rate has been abysmal. Only $30 \%$ of students who entered for the first time in 2000 had graduated in 2004. ${ }^{[1]}$ Consequently, the literature has largely focused on the negative discourse of understanding the hindrance of student success in higher education. This article, however, takes a positive discourse viewpoint in understanding student success in the Bachelor of Emergency Medical Care (BEMC) degree in SA. The BEMC degree is a 4-year paramedic programme undertaken at 4 higher education institutions in SA, i.e. Cape Peninsula University of Technology, Durban University of Technology, Nelson Mandela University and University of Johannesburg. The BEMC provides a foundation in medical sciences, including human anatomy, physiology, pathology and pharmacology, while application to clinical practice becomes more detailed and extensive from the second to the fourth year. From the onset of the programme, students are introduced to key aspects of life support - the theoretical and practical training aspects. The BEMC also includes medical rescue, which is physically demanding and requires students to be physically prepared and able to swim, as they do rescue in the sea, in rivers and/or in dams. A BEMC student may register as an Emergency Care Practitioner (ECP) with the Professional Board for Emergency Care (PBEC), Health Professions Council of South Africa, upon completion of the degree. They practise independently, needing no permission or supervision for the various interventions they perform. The ECP registration is currently the highest registration category with the
PBEC. Given the dearth of ECPs in SA, it may prove useful to understand how BEMC students succeed to increase ECP numbers in the country. We used Deci and Ryan's self-determination theory to explore students' motivation to succeed in the BEMC programme. ${ }^{[2]}$

Self-determination theory suggests that motivation is a two-dimensional concept comprising intrinsic and extrinsic motivation. ${ }^{[3]}$ Intrinsic motivation is defined as being moved by something because it is inherently interesting or satisfying. ${ }^{[4]}$ Vansteenkiste et al ${ }^{[5]}$ state that intrinsic motivation represents the ideal type of motivation because it is fully autonomous and has also been associated with: (i) adaptive metacognitive strategies such as planning and time management; (ii) increased will and determination; (iii) greater intention to persist; and (iv) greater effective perseverance. Intrinsic motivation has also been found to produce positive academic outcomes and to promote a greater conceptual understanding of the learning material than may otherwise have been the case. ${ }^{[6]}$ However, self-determination theory also suggests that higher levels of motivation do not necessarily yield more positive outcomes, as there are other factors that may affect outcomes. ${ }^{[7]}$ For example, a student who is intrinsically motivated may also be unable to concentrate in class due to personal circumstances, thus resulting in poor academic performance.

Organismic integration theory is a sub-theory of self-determination theory that details different forms of extrinsic motivation. Extrinsic motivation is defined as performing an activity to attain some reward or separable outcome. ${ }^{[8]}$ Amotivation refers to the lack of intention to act owing to feelings of incompetence, not valuing the activity or not believing 
the activity will result in a possible outcome. ${ }^{[8,9]}$ The least form of extrinsic motivation is external regulation, in which people's behaviour is controlled by external demand. Therefore, people behave in a certain way to avoid a threatened punishment or to obtain a tangible reward. ${ }^{[10]}$ For example, students may do their homework not because it is the right thing to do but to avoid punishment at school or at home. Introjected regulation refers to people who perform acts as a result of pressure to avoid guilt or to ensure pride or ego-enhancement. For example, a student may study hard to achieve higher marks than his/her colleagues in class to attain pride.

The aim of this study was to explore students' motivation to succeed in the BEMC programme using the self-determination theory.

\section{Methods}

A qualitative approach was used. BEMC students from each of the 4 universities were recruited to participate in the study. Third- and fourth-year students who had not repeated a module/subject while studying for the BEMC degree were purposively sampled and invited to join the focus group discussions. The researchers felt that these students would be best placed to provide answers to the research aim. The first author conducted a total of 7 focus group discussions at the respective institutions during the participants' free time.

The class captains were responsible for co-ordinating the times and meeting venues, as the researchers did not have the participants' contact details, which would have contravened the Protection of Personal Information (POPI) Act, 2013. The class representatives' contact details had been provided by the lecturing staff after consent from the former. The study information had been disseminated to the participants by the class representatives via the lecturing staff. However, the study information was also provided at the beginning of the focus group discussions, which were audio recorded and lasted between 30 and 60 minutes. All focus group discussions were conducted in English.

The audio recordings were transcribed to produce a written text of the focus group discussions. We listened to the recordings and read through the transcripts to ensure accuracy of the latter and to familiarise ourselves with the dataset. Accordingly, the transcripts were not returned to the participants to ensure accuracy, as we had verified the accuracy. The data were analysed using thematic analysis. We developed initial codes using NVivo 11 (Microsoft, USA) after immersing ourselves in the data, and organised the data into meaningful groups. We then sorted the codes into different themes. Themes were reviewed and refined until we were satisfied that these captured the essence of the data.

\section{Ethical approval}

Participation was voluntary and participants could withdraw at any time. Permission to collect data was granted by the respective institutions, while ethical approval was granted by the University of Cape Town Human Research Ethics Committee (ref. no. HREC: 815/2015).

\section{Results and discussion}

\section{Theme 1: Intrinsic motivation}

The thematic analysis that was applied yielded two themes, i.e. intrinsic and extrinsic motivation. Theme 1 considers how the students' intrinsic motivation enabled success in the BEMC programme. The students commented as follows (all names are fictional):
'Well, I started in first year with the goal to complete this course in 4 years, and I think setting yourself a goal does give you a bit of a goal to achieve. So, you're very driven, you're very motivated to achieve that goal, you don't want to slip up anywhere. So, yes, that's the reason why I have possibly come to fourth year in one go, and haven't repeated a year because I did set that goal right at the beginning, right when I was accepted.' (Abel)

'I think on that one also, the mind-set thing, and also people who are internally motivated and you need to do this because, when I started here, swimming was, you know - I mean, it's a black thing. But it was, I mean, if I was thrown into a pool or whatever, I wasn't going to drown, I will do that. But I'm telling you, for me to prepare and get to do it in the times. I'm telling you, I used to do that thing in, like 12 minutes, and when I'm done, like I'm out, you know. Having to learn those tricks about breathing out when you are in there; you know, when you're breathing out the bubbles are disturbing [laughter]. No, I'm telling you. But, looking back today, I go in there and I've got a goal of doing it in 4 minutes, 30 seconds or something, you look at it and you think, yes, it has to be motivation. You know what you want and you're going to work hard and do whatever it takes to get through.' (Todani)

It was clear that both these students had been intrinsically motivated to achieve their goals - completing the course in the minimum time. These findings are consistent with those in the literature. ${ }^{[11-13]}$ Intrinsic motivation means doing something because it is inherently satisfying and this, in turn, results in high-quality learning and innovation. ${ }^{[8]}$ Biggs and Tang ${ }^{[14]}$ argue that intrinsic motivation results in high-quality learning because of the resulting deep approaches to learning.

Self-determination theory suggests that, the more autonomous the motivation, the better the outcome. ${ }^{[4]}$ In other words, the use of intentional agency leads to a better academic outcome than may otherwise have been the case. The desire to succeed was evident in the commitment of Todani, who initially swam $200 \mathrm{~m}$ in $12 \mathrm{~min}$, but 3 years later, was aiming for a time of $4 \mathrm{~min} 30 \mathrm{~s}$, which was less than the required $6 \mathrm{~min}$. In addition, intrinsic motivation is likely to increase with continued success in an activity. This was borne out in the case of Todani, whose swimming time was improving and who had passed successfully. ${ }^{[14]}$ Swimming is part of the BEMC programme requirements for aquatic rescue. Students have to swim $200 \mathrm{~m}$ in $<6 \mathrm{~min}$ to be eligible for entry into the aquatic rescue modules.

The cognitive evaluation theory is considered a sub-theory of the selfdetermination theory and suggests that feelings of competence may enhance intrinsic motivation, as these feelings satisfy a basic psychological need, i.e. competence. ${ }^{[8]}$ However, the cognitive evaluation theory further argues that feelings of competence involve another basic psychological need, i.e. a sense of autonomy, to enhance intrinsic motivation.$^{[8]}$ Lecturers who enjoy their subject and perceive great value in it are likely to inspire their students to become more curious to seek the same worth. ${ }^{[14]}$ This was illustrated by a student who stated that:

'I nearly failed chemistry in high school and, then, first-year chemistry came and I achieved marks in the nineties. The lecturer had the ability to teach so well and her passion shines through, and that also motivates you to acquire the same passion, like, basically, draw from their strength to go on and actually excel.' (Athalia) 
In the education context, intrinsic motivation may result in improved study techniques and intensive studying, which may lead to improved academic performance. ${ }^{[4]}$ Selecting the correct study course also enhances intrinsic motivation, as these students are more likely to succeed than those who made an incorrect study choice. ${ }^{[15]} \mathrm{A}$ particular programme may be appealing at first, but it may become tedious owing to a mismatch between the student's perceived expectations and reality, which may result in failure to progress. It is therefore important to provide accurate information to prospective students so that they can provide informed consent to enrol in the paramedic degree.

\section{Theme 2: Extrinsic motivation}

Some students used extrinsic factors as motivation to succeed in the BEMC programme:

'EMS (emergency medical services) is a bit of a man's world and, as a female and being quite feminine, I enjoy my femininity, it can be quite difficult. But it was a challenge and I have really enjoyed it ... it is equal rights and, as a paramedic, females can also be paramedics. And you have to acknowledge that men have different strengths to women. I don't think it was something to prove but, maybe, to myself, but not to anyone else. It was a challenge.' (Marie)

'I have a learning disability and in high school I had a scribe, as well as a writer on the computer and the papers were read to me, and I got extra time for my papers. But, in high school a lot of, especially pupils, said to me that I would never get tertiary education because I am not clever enough. So, proving everybody else wrong is my kind of own ego boost and just showing everybody else that I am clever enough, that I have the means to get where we are right now.' (Annika)

As mentioned above, there are various types of extrinsic motivation. One can conclude from the abovementioned quotes that these participants exhibited the second type of extrinsic motivation, i.e. introjected regulation. This refers to performing an activity to avoid guilt or to produce egoenhancement or pride. ${ }^{[8]}$ Marie's motivating factor was her stance against gender bias in the masculinised emergency care profession. This emerged in her assertion that 'it is equal rights and, as a paramedic, females can also be paramedics. Therefore, she was using her gender bias stance to motivate her to succeed academically in the BEMC programme.

Annika was dyslexic and had used her learning disability as a motivator to demonstrate that she was capable of obtaining a tertiary qualification, despite her critics. In his book, David and Goliath, Gladwell ${ }^{[16]}$ argues that being dyslexic may be an advantage and that what may appear to give 'giants' their perceived strength, may be their greatest weakness. Gladwell uses the story of David Boies, one of the most famous trial lawyers in the world, to illustrate his point. Boies compensated for his dyslexia by developing the ability to be an effective listener, which made him a good lawyer. It is therefore plausible that Annika had also compensated for her dyslexia by developing abilities she had not realised she possessed. Both Annika and Marie passed the BEMC programme in the minimum period.

Some students indicated that they used their financial circumstances as a motivating factor to apply themselves academically:

'You think of the finances, the strains of it, so we still have siblings that the money is going towards too. So, if you fail, then that just adds to the actual burden on your parents, especially if you are being raised by a single parent, and that salary won't sustain every single child in the household.' (Parsons)

'Another thing I wanted to add to this was that the financial implications too, if you are looking at the younger students, they are being paid for. Whereas us, the more mature guys, it is coming straight from our pockets so we know that there is no way I'm going to repeat a year. My family is going to suffer with me sitting up late and studying, the course is going to be more. There are a whole lot of implications for me if I fail.' (Seth)

Repeating a year was not an option for some of the students, as it would have meant they had to spend an extra year studying, thus leading to increased costs for their families, some of whom were single-parent families. Some of the students were from disadvantaged backgrounds and education was seen as way of improving their socioeconomic situation. These findings are similar to those in the literature, which highlight that students achieved academic success despite their poor background. ${ }^{[11,13]}$ Some of the students in this study indicated that they had to sacrifice time away from family and friends to achieve academic success and that repeating a year would have meant more time away from them. Some had a sponsorship or a bursary that would have lapsed if they failed. This was illustrated by the following student's response:

'My goal was more external. I'm fully sponsored to study, and my sponsor said to me, "If you don't complete it in 4 years, I can't help you; there's nothing I can do"' (Elon)

Another student added to this discussion:

'You know, you're not satisfied with knowing the bare minimum. I'm going to be having people's lives in my hands, but I want to know just enough to potentially save their life.' (Sarai)

Some students, such as Sarai, demonstrated the characteristics of regulation through identification - a more autonomous form of extrinsic motivation. In terms of regulation through identification, the individual has identified the personal value of an activity and accepts the activity as his/her own ${ }^{[8]}$ In other words, Sarai had identified the value of applying herself academically, as she would be performing potentially life-saving interventions that may have adverse outcomes if carried out incorrectly.

\section{Conclusions}

This study explored students' motivation to succeed by obtaining an emergency care degree using the self-determination theory. The twodimensional concepts of self-determination theory, i.e. intrinsic and extrinsic motivation, emerged as themes in this study. Some students were intrinsically motivated to complete the degree in the minimum time. It is more likely that the students' intrinsic motivation increased with continued success during the programme and also satisfied their feelings of competence. Some students succeeded in obtaining the BEMC degree owing to extrinsic motivational factors to either prove some people wrong or because of the financial implications of failing. The emergency care departments need to assist students to maintain motivation, which may satisfy their feelings of autonomy and competence. Addressing students' motivation may allow for more continued success in the academic programme. 


\section{Declaration. None.}

Acknowledgements. The authors wish to acknowledge the respective Emergency Medical Care departments for their unwavering support for this study. We also acknowledge Stevan Bruijns for his valuable contribution to the study.

Author contributions. SS conceptualised the study, collected the data and drafted the manuscript, while BL was responsible for critical revision of the manuscript. Both authors approved the final version.

Funding. This work is based on research supported in part by the National Research Foundation of South Africa for the Thuthuka and Sabbatical grants, unique grant numbers 99322 and 105694.

\section{Conflicts of interest. None.}

1. Scott I, Yeld N, Hendry J. Higher Education Monitor 6: A case for improving teaching and learning in South African higher education. 2007. https://www.che.ac.za/media_and_publications/higher-education-monitor/ higher-education-monitor-6-case-improving-teaching (acessed 30 August 2019).

2. Deci E, Ryan R. Intrinsic Motivation and Self-determination in Human Behavior. New York: Plenum, 1985.

3. Eccles J, Wigfield A. Motivational beliefs, values, and goals. Annu Rev Psychol 2002;53:109-132. https://doi. org/10.1146annurev.psych.53.100901.135153

4. Kusurkar RA, ten Cate TJ, Vos CMP, et al. How motivation affects academic performance: A structural equation modelling analysis. Adv Health Sci Educ 2013;18(1):57-69. https://doi.org/10.1007/s10459-012-9354-3
5. Vansteenkiste M, Sierens E, Soenens B, et al. Motivational profiles from a self-determination perspective: The quality of motivation matters. J Educ Psychol 2009;101(3):671-688. https://doi.org/10.1037/a0015083

6. Trevino NN, Defreitas SC. The relationship between intrinsic motivation and academic achievement for fir generation Latino college students. Soc Psychol Educ 2014;17(2):293-306. https://doi.org/10.1007/s11218-013-9245-3 7. Deci E, Ryan R. The 'what' and 'why' of goal pursuits: Human needs and the self-determination of behavio Psychological Inquiry 2009;11(4):227-268. https://doi.org/10.1207/S15327965PLI1104_01

8. Ryan R, Deci E. Intrinsic and extrinsic motivations: Classic definitions and new directions. Contemp Educ Psychol 2000;25(1):54-67. https://doi.org/10.1006/ceps.1999.1020

9. Ryan R. Psychological needs and the facilitation of integrative processes. J Personality 1995;63(3):397-427. https://doi.org/10.1111/j.1467-6494.1995.tb00501.x

10. Deci E, Vansteenkiste M. Self-determination theory and basic need satisfaction: Understanding human development in positive psychology. Ric di Psicol 2004;27(1):23-40.

11. Dass-Brailsford P. Exploring resiliency: Academic achievement among disadvantaged black youth in South Africa. S Afr J Psychol 2005;35(3):574-591. https://doi.org/10.1177/008124630503500311

12. McGhie V. Factors impacting on first-year students' academic progress at a South African University. PhD thesis. Cape Town: Stellenbosch University, 2012

13. Vincent L, Idahosa G. Joining the academic life: South African students who succeed at university despite not Vincent L, Idahosa G. Joining the academic life: South African students who succeed at university despite no
meeting standard entry requirements. S Afr J High Educ 2014;28(4):1433-1447. https:// doi.org/10.20853/28-4-393 14. Biggs J, Tang C. Teaching for Quality Learning at University: What the Student Does. 3rd ed. New York: Society for Research into Higher Education and Open University Press, 2007.

15. Jones B, Coetzee G, Bailey, et al. Factors that Facilitate Success for Disadvantaged Higher Education Students: An Investigation into Approaches used by REAP, NSFAS and Selected Higher Education Institutions. Cape Town Rural Education Access Programme, 2008.

16. Gladwell M. David and Goliath: Underdogs, Misfits, and the Art of Battling Giants. New York: Little, Brown and Company, 2013.

Accepted 1 July 2019 